\title{
Persantunan
}

Kami berterima kasih kepada para mitra bebestari yang telah berkenan meluangkan waktu serta mencurahkan tenaga dan pikiran untuk menelaah dan menilai kelayakan artikel yang diterbitkan pada Jurnal Iktiologi Indonesia Volume 18 Nomor 2 Bulan Juni Tahun 2018, yaitu:

Akhmad Fairus Mai Soni, Dr. (Balai Besar Perikanan Budidaya Air Payau)

Andi Iqbal Burhanuddin, Prof. Dr. (Fakultas Ilmu Kelautan dan Perikanan, Universitas Hasanuddin)

Asda Laining, Dr. (Balai Penelitian dan Pengembangan Budi Daya Payau)

Djumanto, Dr. (Fakultas Pertanian, Universitas Gajah Mada)

Endang Dewi Masithoh, Dr (Fakultas Perikanan dan Kelautan, Universitas Airlangga)

Fadly Y.Tantu, Dr. (Program Studi Akuakultur, Fakultas Peternakan dan Perikanan - Universitas Tadulako)

Gybert E. Mamuaya, Dr. (Fakultas Perikanan dan Kelautan, Universitas Sam Ratulangi)

Gunawan Pratama Yoga, Dr. (Pusat Penelitian Limnologi - Lembaga Ilmu Pengetahuan Indonesia

Kadarusman (Akademi Perikanan Sorong)

Lenny S. Syafei, Dr. (Masyarakat Iktiologi Indonesia, Bogor)

M. F. Rahardjo, Prof. Dr. (Departemen Manajemen Sumber Daya Perairan, Fakultas Perikanan dan Ilmu Kelautan, Institut Pertanian Bogor)

Usman Muhammad Tang, Prof. Dr. (Fakultas Perikanan dan Ilmu Kelautan - Universitas Riau) 



\section{PANDUAN bagi PENULIS}

Jurnal $\mathfrak{Z}$ kttiologi $\mathfrak{Z}$ ndonesia (JII) menyajikan artikel yang berkenaan dengan segala aspek kehidupan ikan (Pisces) di perairan tawar, payau, dan laut. Aspek yang dicakup antara lain biologi, fisiologi, taksonomi dan sistematika, genetika, dan ekologi, serta terapannya dalam bidang penangkapan, akuakultur, pengelolaan perikanan, dan konservasi. Artikel yang dimuat merupakan hasil lengkap suatu penelitian. Resensi buku yang berkaitan dengan aspek-aspek di atas dapat dimuat asalkan tidak melebihi dua halaman. Ulas balik (review) suatu topik yang dipandang penting dimuat hanya atas permintaan dewan penyunting.

JII diterbitkan tiga kali setahun (Februari, Juni, dan Oktober). Pada nomor terakhir tiap volume dimuat daftar isi, indeks penulis, dan indeks subyek.

Artikel dapat ditulis dalam Bahasa Indonesia atau Bahasa Inggris. Artikel belum pernah diterbitkan pada media manapun. Penyunting berhak menerima atau menolak artikel berdasarkan kesesuaian materi dengan ruang lingkup JII, dan meringkas atau menyunting artikel bila diperlukan untuk menyesuaikan dengan halaman yang tersedia tanpa mengaburkan substansi. Opini yang tertuang dalam tulisan artikel tidak menggambarkan kebijakan penyunting.

Untuk semua keperluan, penulis pertama dianggap sebagai penulis korespondensi artikel, kecuali ada keterangan lain. Penulis, yang artikelnya disetujui untuk diterbitkan, bersedia mengalihkan hak cipta naskah kepada penerbit (Masyarakat Iktiologi Indonesia). Cetakan awal akan dikirimkan kepada penulis korespondensi melalui surat elektronik untuk mendapatkan tanggapan. Tanggapan penulis dan surat persetujuan pengalihan hak cipta segera dikirim ke penyunting dalam waktu satu minggu.

Dalam hal penemuan baru, disarankan kepada penulis untuk mengurus hak patennya sebelum mempublikasikan dalam jurnal ini.

\section{Pengajuan naskah}

Pengajuan naskah dilakukan dengan mengirimkan satu salinan lunak (soft copy) melalui surat elektronik kepada dewan penyunting JII. Pengajuan naskah dapat dilakukan kapan pun kepada:

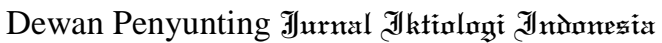

Gd. Widyasatwaloka, Bidang Zoologi, Pusat Penelitian Biologi LIPI

Jln. Raya Jakarta-Bogor Km 46, Cibinong 16911

凶iktiologi_indonesia@yahoo.co.id Telp. (021) 8765056/64, Fax. (021) 8765068
Naskah yang diterima penyunting akan ditelaah oleh dua mitra bebestari anonim yang kompeten untuk memperoleh penilaian konstruktif agar mendapatkan suatu baku publikasi yang tinggi.

Panduan berikut membantu anda dalam penyiapan naskah yang akan dikirim ke JII. Panduan lengkap dapat anda lihat pada laman Masyarakat Iktiologi Indonesia (www.iktiologi-indonesia.org). Naskah yang ditulis sesuai dengan ketentuan pada panduan akan mempercepat waktu pemeriksaan dan penyuntingan.

\section{Penyiapan naskah}

Pastikan bahwa naskah cukup jelas untuk disunting, dengan mengikuti hal berikut:

- Ukuran kertas: A4 dengan batas pinggir $3 \mathrm{~cm}$ seluruhnya, bernomor halaman yang dituliskan pada ujung kanan bawah.

- Naskah ditulis dalam satu kolom pada tiap halaman.

- Naskah diketik menggunakan Microsoft Word for Windows dalam spasi 1,5 baris, tipe huruf Times New Roman ukuran 12. Karakter huruf pada Gambar dapat berbeda dari ketentuan ini.

- Teks dituliskan hanya rata kiri.

- Gunakan spasi tunggal (bukan ganda) sesudah tanda baca (titik, koma, titik dua, titik koma).

- Gunakan satuan Sistem Internasional (SI) untuk pengukuran dan penimbangan.

- Nama ilmiah organisme disesuaikan dengan kode nomenklatur internasional (e.g. International Code of Zoological Nomenclature). Nama genus dan spesies ditulis dalam huruf miring (italik).

- Angka yang lebih kecil dari 10 dieja, misal tujuh spesies ikan, tetapi tidak dieja bila diikuti oleh satuan baku, misal $3 \mathrm{~kg}$. Nilai di atas sembilan ditulis dalam angka, kecuali pada awal kalimat.

- Tidak menggunakan garis miring (sebagai ganti kata per), tetapi menggunakan tika atas indeks minus, contoh $9 \mathrm{~m} / \mathrm{det}$ dituliskan $9 \mathrm{~m} \mathrm{det}^{-1}$.

- Jangan menggunakan singkatan tanpa keterangan sebelumnya. Kata yang disingkat sebaiknya ditulis lengkap pada penyebutan pertama diikuti singkatan dalam tanda kurung.

- Tanggal ditulis sebagai 'hari bulan tahun', misal 12 September 2010. Singkatan bulan pada tabel dan gambar menggunakan tiga kata pertama nama bulan, misal Jan, Apr, Agu.

- Peta memuat petunjuk garis lintang dan garis bujur, serta menyebutkan sumber data.

- Gambar atau foto organisme atau bagian organisme harus diberi keterangan skala.

- Periksa untuk memastikan bahwa gambar telah diberi nomor secara benar seperti yang dikutip dalam teks. Nomor dan judul gambar terletak di bagian bawah gambar.

- Pastikan bahwa tabel telah diberi nomor dengan benar dan berurutan sesuai dengan nomor 
yang dikutip dalam teks. Posisi nomor dan judul tabel terletak di atas tabel. Judul sebaiknya jelas, lengkap dan informatif. Letakkan sumber data dan catatan tepat di bawah tabel. Jangan memuat garis vertikal pada tabel. Hilangkan garis horisontal dari tabel, kecuali garis atas dan bawah judul kolom dan garis akhir dasar tabel.

- Ketepatan pengutipan pustaka sepenuhnya menjadi tanggung jawab penulis. JII menganut sistem nama-tahun dalam pengutipan. Nama keluarga dan tahun publikasi dicantumkan dalam teks eg. Rahardjo \& Simanjuntak (2007) atau (Rahardjo \& Simanjuntak 2007) untuk satu dan dua penulis; Sjafei et al. (2008) atau (Sjafei et al. 2008) untuk penulis lebih dari dua. Penulisan banyak pustaka kutipan dalam teks diurutkan dari yang tertua eg. (Gonzales et al. 2000, Stergiou \& Moutopoulos 2001, Khaironizam \& NormaRashid 2002, Abdurahiman et al. 2004, Frota et al. 2004; dan Tarkan et al. 2006). Pustaka bertahun sama disusun berurut menurut abjad penulis. Pustaka dari penulis yang sama dan dipublikasikan pada tahun yang sama dibedakan oleh huruf kecil (a, b, c dan seterusnya) yang ditambahkan pada tahun publikasi.

\section{Bagian-bagian naskah}

Judul ditulis di tengah dengan huruf tebal berukuran 13 dan terjemahan ditulis dengan huruf biasa berukuran 11. Judul hendaknya singkat, tepat, dan informatif yang mencerminkan isi artikel.

Nama penulis ditulis dengan huruf biasa berukuran 12. Alamat ditulis dengan huruf biasa berukuran 9, yang memuat nama dan alamat lembaga disertai kode pos. Khusus penulis untuk berkorespondensi disertai alamat surat elektronik.

Abstrak ditulis dalam Bahasa Indonesia dan Inggris tidak melebihi 250 kata. Abstrak memuat tujuan, apa yang dilakukan (metode), apa yang ditemukan (hasil), dan simpulan. Hindari singkatan dan kutipan pustaka. Abstrak terdiri atas satu alinea.

Kata penting ditulis dalam Bahasa Indonesia dan Inggris tidak melebihi tujuh kata yang disusun menurut abjad.

Pendahuluan menjelaskan secara utuh dan jelas alasan mengapa studi dilakukan. Hasil-hasil sebelumnya yang terkait dengan studi anda dirangkum dalam suatu acuan yang padat. Nyatakan tujuan penelitian anda.

Bahan dan metode dituliskan secara jelas. Teknik statistik diuraikan secara lengkap (jika baru) atau diacu.

Hasil. Di sini anda kemukakan informasi dan hasil yang diperoleh berdasarkan metode yang digunakan. Jangan mengutip pustaka apapun pada bab ini.

Pembahasan. Nilai suatu naskah ditentukan oleh suatu pembahasan yang baik. Di sini hasil studi anda dihubungkan dengan hasil studi sebelumnya. Hasil diinterpretasikan dengan dukungan kejadian atau pustaka yang memadai. Hasil yang tidak diharapkan atau anomali perlu dijelaskan. Penggunaan pustaka primer mutakhir (10 tahun terakhir) sangat dianjurkan. Jika dimungkinkan, sitir ide atau gagasan yang dimuat pada JII terbitan terdahulu terkait dengan topik anda.

Simpulan dinyatakan secara jelas dan ringkas, serta menjawab tujuan peneltian.

Persantunan (bila perlu) memuat lembaga atau orang yang mendukung secara langsung penelitian atau penulisan naskah anda.

Daftar pustaka disusun menurut abjad nama penulis pertama. Pastikan semua pustaka yang dikutip dalam teks tertera di daftar pustaka, dan demikian pula sebaliknya.

- Judul terbitan berkala dikutip lengkap (ditulis dalam huruf italik), yang diikuti oleh volume dan nomor terbitan, serta nomor halaman dalam huruf roman (tegak). Contoh:

Lauer TE, Doll JC, Allen PJ, Breidert B, Palla J. 2008. Changes in yellow perch length frequencies and sex ratios following closure of the commercial fishery and reduction in sport bag limits in southern Lake Michigan. Fisheries Management and Ecology, 15(1): 39-47

- Judul buku ditulis dalam huruf italik. Gunakan huruf kapital pada awal kata, kecuali kata depan dan kata sambung. Nama dan lokasi penerbit, serta total halaman dicantumkan. Contoh:

Berra TB. 2001. Freshwater Fish Distribution. Academic Press, San Francisco. $640 \mathrm{p}$.

- Buku terjemahan ditambahkan nama penerjemahnya. Contoh:

Nikolsky GV. 1963. The ecology of fishes. Translated from Russian by L. Birkett. Academic Press, London and New York. $352 \mathrm{p}$.

Steel GD, Torrie JH. 1981. Prinsip-prinsip dan Prosedur Statistika. Diterjemahkan oleh Bambang Sumantri. PT. Gramedia Pustaka Utama. Jakarta. 747 p.

- Artikel yang termuat dalam kumpulan monograf (buku, prosiding) dituliskan: penulis-tahun, judul artikel. In: nama penyunting, judul monograf (ditulis dengan huruf italik), nama penerbit dan lokasinya, serta halaman artikel. Contoh:

Bleckmann H. 1993. Role of lateral line in fish behaviour. In: Pitcher TJ (ed.). Beha- 
viour of Teleost Fishes. Chapman and Hall, London. pp. 201-246.

Simanjuntak CPH, Zahid A, Rahardjo MF, Hadiaty RK, Krismono, Haryono, Tjakrawidjaja AT (Editor). 2011. Prosiding Seminar Nasional Ikan VI. Bogor 89 Juni 2010. Masyarakat Iktiologi Indonesia. Cibinong. 612 p.

- Kutipan terbatas hasil yang tak dipublikasikan, pekerjaan yang dalam penyiapan, pe- kerjaan yang baru diusulkan, atau komu-nikasi pribadi hanya dibuat dalam teks, di luar Daftar Pustaka.

- Artikel dan buku yang belum dipublikasikan dan sedang dalam proses pencetakan diberi tambahan "in press".

Khusus artikel ulas balik suatu topik dan resensi buku tidak perlu mengikuti sistematika penulisan di atas. 


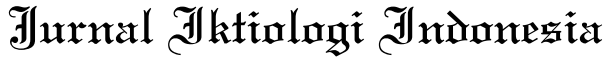

Volume 18 Nomor 2 Juni 2018

Jusmaldi, Nova Hariani Hubungan panjang bobot dan faktor kondisi ikan wader bintik dua Barbodes binotatus (Valenciennes, 1842) di Sungai Barambai Samarinda Kalimantan Timur [Length-weight relationship and condition factor of spotted barb Barbodes binotatus (Valenciennes, 1842) in Barambai River Samarinda East Kalimantan $] \ldots \ldots \ldots \ldots \ldots \ldots \ldots \ldots \ldots \ldots \ldots \ldots$

D. Arfiati, U. Zakiyah, I. S. Nabilah, N. Khoiriyah, A. S. Jayanti, H. F. Kharismayanti Perbandingan LC50 - 96 jam terhadap mortalitas benih ikan mas (Cyprinus carpio Linnaeus 1758) pada limbah penyamakan kulit dan insektisida piretroid [Comparison of lethal concentrations ( $\mathrm{LC}_{50}-96$ H) toward common carp, Cyprinus carpio Linnaeus 1758 mortality in leather industry liquid waste and

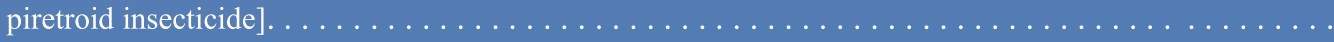

Khaerudin, Afreni Hamidah, Winda Dwi Kartika Jenis-jenis ikan hasil tangkapan nelayan di Kecamatan Tungkal Ilir Kabupaten Tanjung Jabung Barat, Provinsi Jambi [Fish species of fishermens' catches in Kuala Tungkal - Tungkal Ilir Sub-District, Tanjung Jabung Barat Regency, Jambi Province]

Anugerah Saputra, Astri Wulandari, Ernawati, Muhammad Amri Yusuf, Irvan Eriswandy, Andi Aliah Hidayani Penjantanan ikan gapi (Poecilia reticulata Peters, 1859) dengan pemberian ekstrak jeroan teripang pasir (Holothuria scabra) [Masculinization of guppy fish (Poecilia reticulata Peters, 1859) with extract of sea cucumber (Holothuria scabra) $] \ldots \ldots \ldots \ldots \ldots \ldots \ldots \ldots \ldots$

Ilham Zulfahmi, Yusrizal Akmal, Agung Setia Batubara Morfologi tulang belakang (ossa vertebrae) ikan keureling, Tor tambroides (Bleeker, 1854) [The morphology of Thai mahseer's Tor tambroides (Bleeker, 1854) axial skeleton (ossa vertebrae) $] \ldots \ldots \ldots \ldots \ldots \ldots \ldots \ldots \ldots \ldots$

Arief Wujdi, Maya Agustina, Irwan Jatmiko Indeks bentuk otolit ikan cakalang, Katsuwonus pelamis Linnaeus, 1758 dari Samudra Hindia [Otolith shape indices of skipjack tuna, Katsuwonus pelamis (Linnaeus, 1758) from the Indian Ocean $] \ldots \ldots \ldots \ldots \ldots \ldots \ldots \ldots \ldots \ldots \ldots \ldots \ldots \ldots$

Dwinda Pangentasari, Mia Setiawati, Nur Bambang Priyo Utomo, Mas Tri Djoko Sunarno Komposisi dan nilai kecernaan nutrien tepung daun tarum (Indigofera zollingeriana) yang difermentasi dengan cairan rumen domba pada benih ikan jelawat Leptobarbus hoevenii (Bleeker, 1851) [Composition and digestibility values of Indigofera zollingeriana leaf meal on hoven's carp seed Leptobarbus hoevenii which fermented with sheep rumen liquor $] \ldots \ldots \ldots \ldots \ldots \ldots \ldots \ldots \ldots$

Renny Kurnia Hadiaty Status taksonomi iktiofauna endemik perairan tawar Sulawesi [Taxonomical status of endemic freshwater ichthyofauna of Sulawesi $] \ldots \ldots \ldots \ldots \ldots \ldots \ldots \ldots$ 